Article

\title{
Design of an Isolated Bidirectional Symmetric Resonant Converter
}

\author{
Yih-Her Yan ${ }^{1}{ }^{\oplus}$, Hung-Liang Cheng ${ }^{2}{ }^{\oplus}$, Shun-Yu Chan ${ }^{3}$, Yu-Da Chen ${ }^{1}$ and \\ Yong-Nong Chang $1, * \mathbb{D}$ \\ 1 Department of Electrical Engineering, National Formosa University, Hu-Wei, Yunlin 63201, Taiwan; \\ yanyh@nfu.edu.tw (Y.-H.Y.); 40325131@gm.nfu.edu.tw (Y.-D.C.) \\ 2 Department of Electrical Engineering, I-Shou University, Kaohsiung 84001, Taiwan; hlcheng@isu.edu.tw \\ 3 Department of Electrical Engineering, Cheng Shiu University, Kaohsiung 83347, Taiwan; \\ k0070@gcloud.csu.edu.tw \\ * Correspondence: ynchang@nfu.edu.tw; Tel.: +886-5-631-5637
}

Received: 28 August 2020; Accepted: 13 November 2020; Published: 17 November 2020

check for updates

\begin{abstract}
An isolated type bidirectional resonant converter is presented in this paper. Using a dual active bridge as the main topology and integrating symmetric resonant mechanism, the developed converter features an isolated type bidirectional resonant converter with bidirectional power conversion and electrical isolation capabilities to ensure working security and stability. The application of a symmetric resonant scheme enables the control range of input and output voltages to be widened and achieves soft switching during bidirectional power conversion. A converter design process covering all the bases is exhibited in this work. With the digital signal processor (DSP) TMS320F28335 being employed as the control core, the developed isolated bidirectional resonant converter can effectively handle the power conversion between the simulated $400 \mathrm{~V}$ DC grid and the energy storage battery ranging from 280 to $403 \mathrm{~V}$. Based on a $1 \mathrm{~kW}$ capacity design, the test data reveal that the forward conversion efficiency from grid to battery can reach $93.25 \%$, and the reverse conversion efficiency from battery to grid is as high as $94.60 \%$.
\end{abstract}

Keywords: bidirectional converter; symmetric resonant circuit; zero-voltage switching; zero-current switching

\section{Introduction}

Most of the conventional renewable energy storage system is made up of multiple converters [1] with at least one for storage and another for supply. The essential power conversion circuits lead to cost and size increase. The introduction of a bidirectional converter $[2,3]$ with bidirectional power propagation ability can effectively overcome these problems and enhance the conversion efficiency.

Refs. [4-6] are articles regarding dual active bridge (DAB) design; these circuits are featured with simple structure, easy control, and bidirectional power flow. However, there exist some problems in a single-phase shift controller, such as a narrower voltage range at light load and curtailed efficiency owing to hard switching. In the case of renewable energy regulation applications, hard switching might usually yield the current waveform to be square or sawtooth, thus invoking high-frequency electromagnetic interference (EMI) and excessive switching loss.

Resonant converters possess a soft switching feature and thus have merits of power loss reduction, with the inductor-inductor-capacitor (LLC) resonant topology being the most popular one. In charger applications, various schemes including LCC, LLC, CLLC, CLLLC, etc., have been proposed [7-10]. Owing to the advantages of soft-switching characteristic and easy control, the LCC and/or CLLC converter are popularly used in many applications. However, due to the low voltage gain in reverse 
operation, they are not suitable for bidirectional converter designs [11-13]. In the bidirectional power transfer applications [14-16], the LLC resonant converter is forced to turn into LC resonant, owing to the magnetizing inductance being clamped by the output voltage. Thus, the voltage gain is limited to be less than 1 in the backward power transfer mode, and only zero-voltage switching (ZVS) of power switches can be achieved. The lack of zero-current switching (ZCS) on the secondary rectifying devices leads to a reduction of conversion efficiency and is unsuitable for wide voltage range applications. Plus, the bidirectional LLC resonant converter is always unsymmetrical and thus results in the difficulty of a bidirectional design. Moreover, LLC only possesses the LC feature in the reverse operating mode and has limited operating range, with the voltage gain being less than 1.0. Therefore, the CLLLC design is more suitable for a bidirectional converter with wider wide operating range [17].

An isolated type bidirectional resonant converter is developed in this paper to tackle the inherited problems faced. Compared with the bidirectional LLC resonant topology, the developed bidirectional symmetric resonant converter allows the voltage gain to be greater than 1 in the reverse mode and achieves soft switching at a full range of load as well as keeps high conversion efficiency in large power applications. Moreover, the symmetric circuit topology makes the circuit design easier and suits the bidirectional operation and wide voltage range applications.

This research principally aims at realizing a CLLLC topology, which is more suitable than LLC in accomplishing bidirectional conversion. A detailed bidirectional resonant converter design procedure is revealed, and the component parameters are derived theoretically and then validated in practice. Finally, an isolated type bidirectional resonant converter is implemented with its performance being exhibited.

\section{Circuit Structure and Operation Analysis}

\subsection{Circuit Structure}

Evolved from an LLC resonant converter, rectification diodes of the transformer secondary side are replaced by active power switches, and an inductor is introduced into the secondary side to form a resonant tank along with the resonant capacitor. Figure 1 shows the realized topology of the isolated bidirectional symmetric resonant converter with a dual active full bridge. In definition, forward charging mode is the power transfer from power grid $V_{D C_{-} G r i d}$ to battery port $V_{B a t}$, and reverse discharging mode marks the power transfer reversely. With the usage of the symmetric resonant scheme, the power switches can achieve soft switching in either direction of power transfer and thus reduce the switching losses and EMI. Figure 2 illustrates the voltage gain curves of the traditional LLC resonant converter; the reverse-mode voltage gain is limited to be less than 1 .

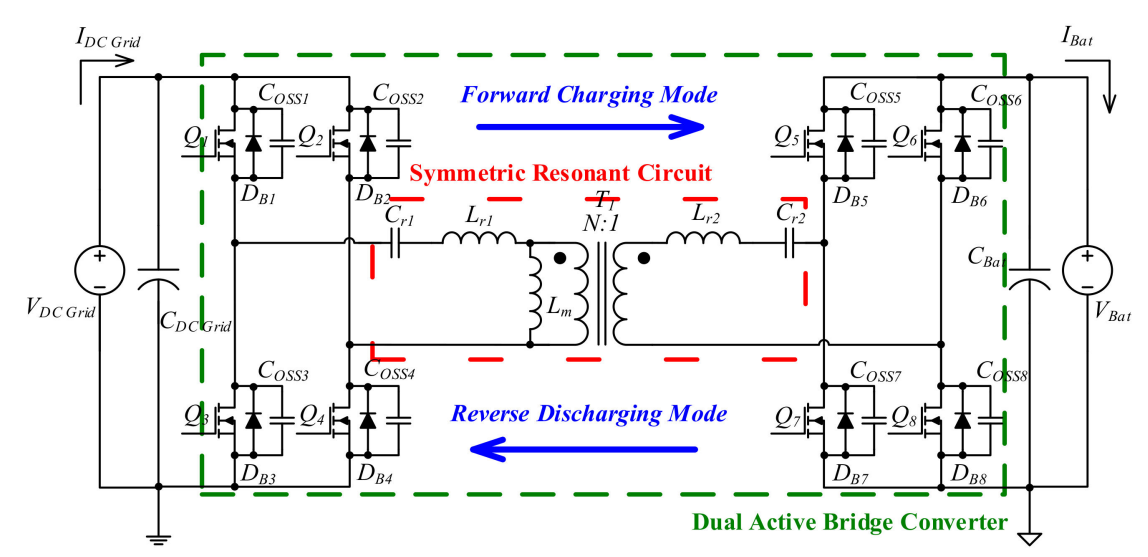

Figure 1. The proposed isolated bidirectional symmetric resonant converter with dual active full bridge. 


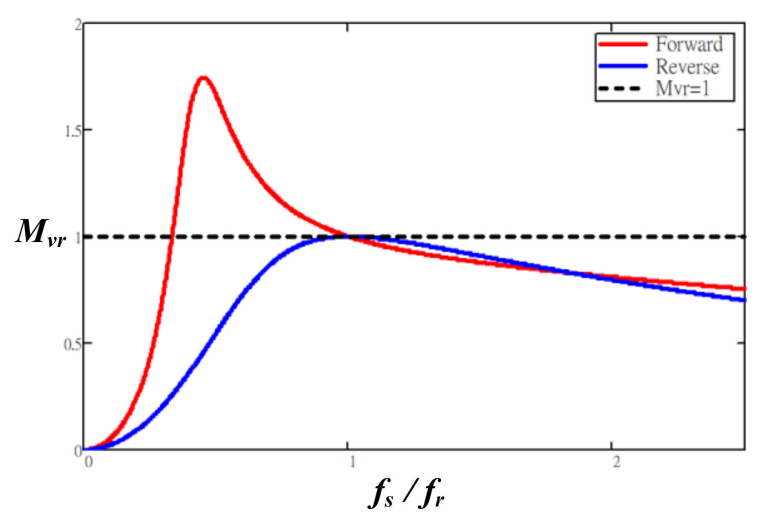

Figure 2. Voltage gain of LLC resonant converter at forward and reverse modes.

\subsection{Description of Operating Range}

Figure 3 shows the voltage gain profile in the forward mode of the proposed isolated bidirectional symmetric resonant converter. It is conducted and completed by applying Mathcad and simulated software. The magnitude of voltage gain depends on the ratio of the switching frequency with respect to the resonant frequency. According to the frequency ratio, Region I only ensures ZVS. Region II ensures ZVS of power switches and ZCS of the diodes. Region III exhibits large voltage variation with only ZCS of the diodes. Therefore, Region III should be avoided for voltage control consideration [18]. Due to the symmetric feature, the description is suitable for the reverse mode as well.

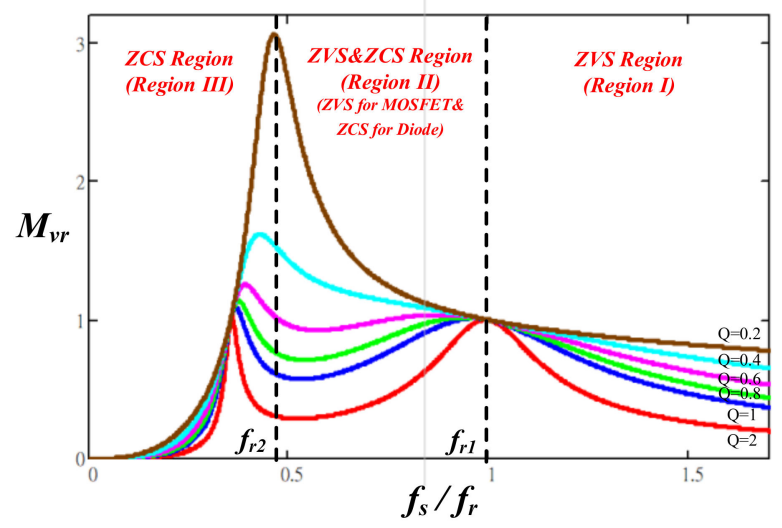

Figure 3. Voltage gain profile in the forward mode of the proposed bidirectional symmetric resonant converter.

\subsection{Description of Operating Range}

Figure 4 shows the power propagation of the forward charging mode. The energy on the DC grid $V_{D C_{-} \text {Grid }}$ supplies energy via power switches $Q_{1}, Q_{2}, Q_{3}$, and $Q_{4}$; it passes from the transformer primary side to the secondary side and thus is rectified by the intrinsic diodes $D_{B 5}, D_{B 6}, D_{B 7}$, and $D_{B 8}$ to charge the battery $V_{B a t}$. By adjusting the switching frequency, the output voltage and output power are controlled accordingly. The trigger signals of $Q_{1}-Q_{4}$ are a pair of symmetric square waves with each being around a $50 \%$ duty ratio. With $Q_{1}$ and $Q_{4}$ being a group and $Q_{2}$ and $Q_{3}$ being another, the trigger signals of $Q_{1}$ and $Q_{2}$ are displaced by $180^{\circ}$, and an appropriate dead time is introduced therein. Due to the symmetric feature, the reverse discharging mode will apply the same operation. Therefore, only the forward mode operating in Region II is used to describe the operating principle. Figure 5 illustrates the important theoretic waveforms. For simplifying the analysis, the following assumptions must be made: 
1. The circuit operates in the steady state.

2. Only intrinsic diode $D_{B}$ and parasitic capacitance $C_{O S S}$ are taken into account with others being ignored.

3. The effect of the parasitic capacitances $C_{O S S 1}-C_{O S S 8}$ is neglected.

4. All devices are ideal.

5. The output capacitances $C_{D C_{-} \text {Grid }}$ and $C_{B a t}$ are large enough to look upon $V_{D C_{-} G r i d}$ and $V_{B a t}$ as the ideal voltage source.

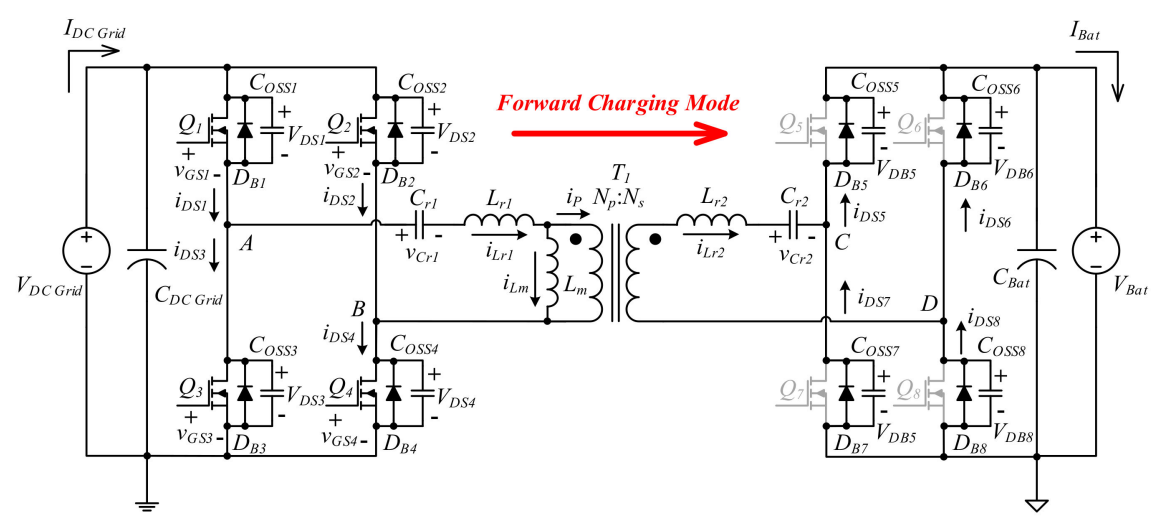

Figure 4. Power propagation of the forward charging mode.

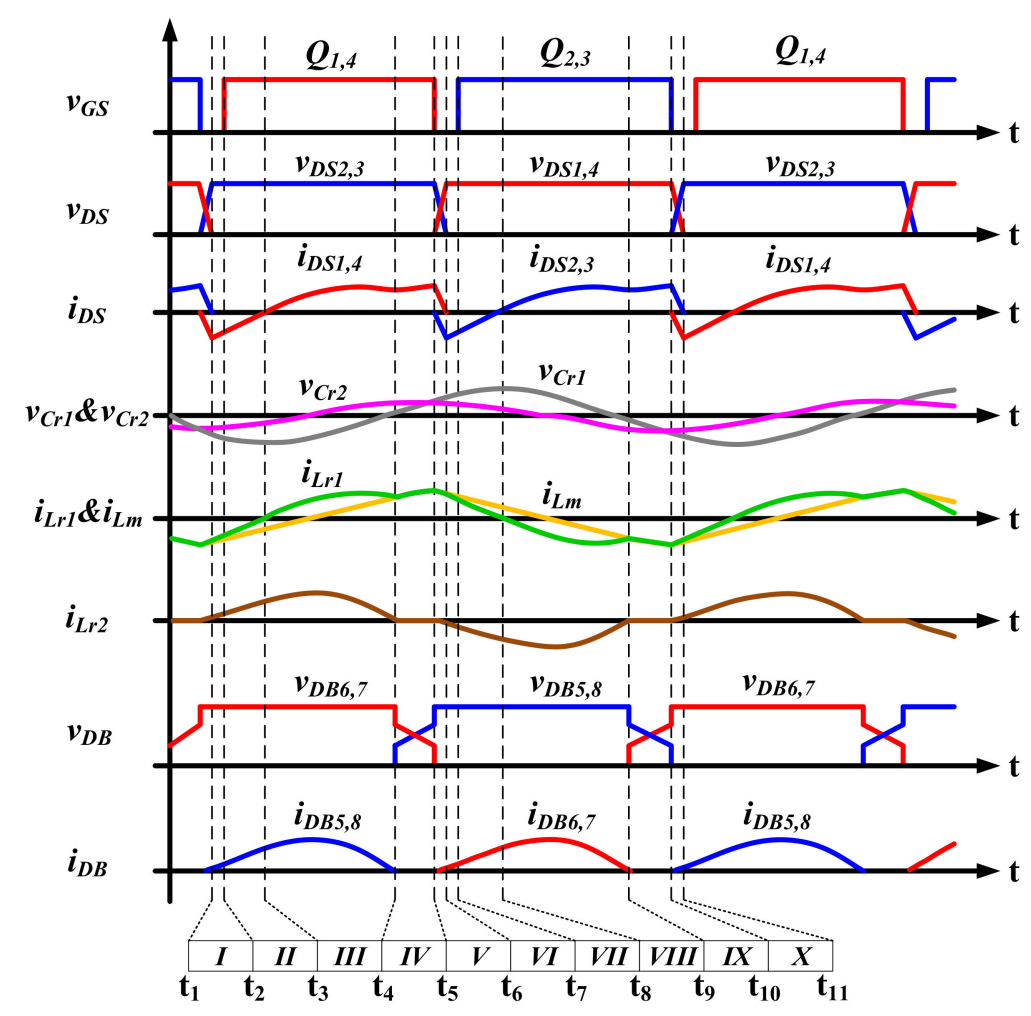

Figure 5. Important theoretic waveforms operating in Region II.

\subsubsection{Stage $\mathrm{I}\left[t_{1}<t \leq t_{2}\right]$}

In this stage, Figure 6a shows that $Q_{1}, Q_{2}, Q_{3}$, and $Q_{4}$ are all cut off. At the secondary side, $D_{B 5}$ and $D_{B 8}$ conduct, while $D_{B 6}$ and $D_{B 7}$ remain cut off. At the primary side, the resonant current $i_{L r 1}$ passes through $D_{B 1}$ and $D_{B 4}$ to keep the resonant current flow and prevent the devices from voltage spike 
damage. In addition, the circuit is ready for the ZVS of $Q_{1}$ and $Q_{4}$. At $t=t_{2}$, as gate signals $v_{G S 1}$ and $v_{G S 4}$ turn from low level to high, the next stage follows.

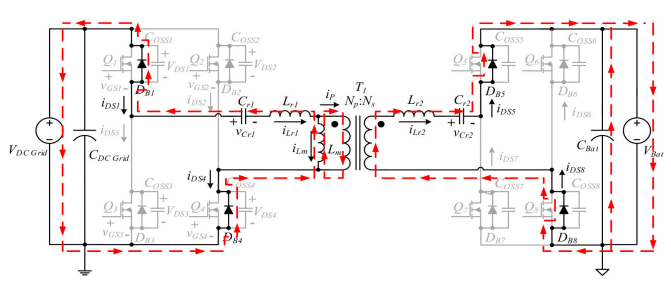

(a)

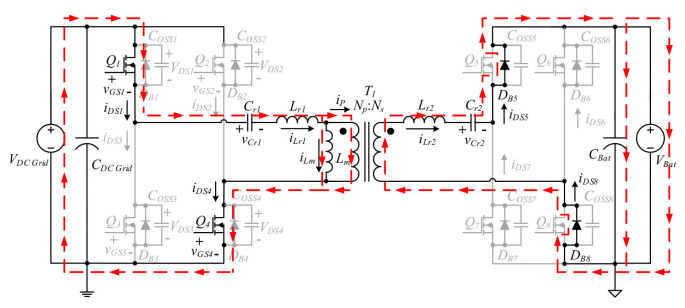

(c)

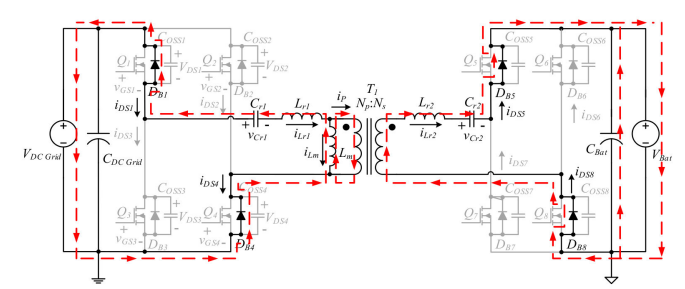

(b)

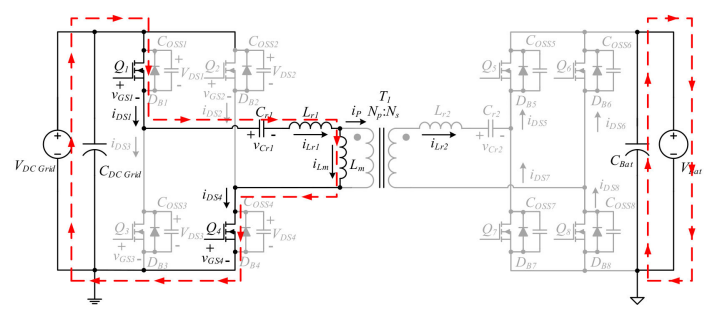

(d)

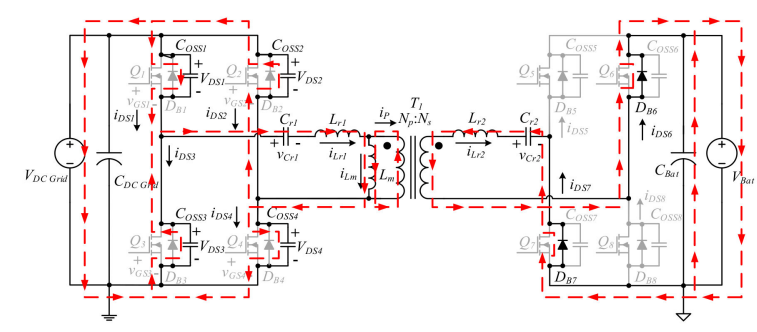

(e)

Figure 6. The conduction path of each stage in Region II: (a) Stage I conduction path; (b) Stage II conduction path; (c) Stage III conduction path; (d) Stage IV conduction path; (e) Stage V conduction path.

\subsubsection{Stage II $\left[t_{2}<t \leq t_{3}\right]$}

As shown in Figure $6 \mathrm{~b}, Q_{1}-Q_{4}$ remain at the cut-off state. The intrinsic diodes $D_{B 5}$ and $D_{B 8}$ keep on conducting while $D_{B 6}$ and $D_{B 7}$ remain at the cut-off state. The resonant current $i_{L r 1}$ flows via intrinsic diodes $D_{B 1}$ and $D_{B 4}$ to retain the conduction loop. As the power switch turns on at the end at $t=t_{3}$, the ZVS is realized, whereas due to the magnetizing inductor $L_{m}$ being clamped by the output voltage $V_{B a t}$ and the secondary resonant capacitor voltage $V_{C r 2}, L_{m}$ is absent from resonating, and thus $i_{L m}$ keeps on rising linearly. At $t=t_{3}$, resonant current $i_{L r 1}$ approaches 0 , and this stage ends.

\subsubsection{Stage III $\left[t_{3}<t \leq t_{4}\right]$}

As shown in Figure $6 c, Q_{1}$ and $Q_{4}$ turn on at $t=t_{3}$ and achieve ZVS while $Q_{2}$ and $Q_{3}$ remain at the cut-off state. In this stage, $V_{D C}$ Grid passes the energy through $C_{r 1}, L_{r 1}, C_{r 2}$, and $L_{r 2}$, and it delivers the energy to the battery side via the isolated transformer. After being rectified by intrinsic diodes $D_{B 5}$ and $D_{B 8}$, the energy charges the battery, whereas $L_{m}$ is absent from resonating due to the magnetizing inductor $L_{m}$ being clamped by the output voltage $V_{B a t}$ and the secondary resonant capacitor voltage 
$V_{C r 2}$, and thus $i_{L m}$ keeps on rising linearly. At $t=t_{4}, i_{L r 1}$ equals $i_{L m}$, and this stage terminates. In the meantime, current $i_{D B 5,8}$ falls to 0 , and thus ZVS is achieved.

\subsubsection{Stage IV $\left[t_{4}<t \leq t_{5}\right]$}

As shown in Figure 6d, $Q_{1}$ and $Q_{4}$ remain conducting while $Q_{2}$ and $Q_{3}$ remain at the cut-off state. As $i_{L r 1}$ equals $i_{L m}$ at $t=t_{4}$, the transformer is decoupled, and electromagnetic induction takes a break. The secondary side bridge is temporarily disabled without current flow. The $D_{B 5}$ and $D_{B 8}$ is naturally cut off and gets ready for ZCS. In this mode, the transformer does not transfer energy to the load, and the magnetizing inductor $L_{m}$ is not clamped by the output voltage $V_{B a t}$ and the secondary resonant capacitor voltage $V_{C r 2}$. The magnetizing inductor $L_{m}, L_{r 1}$, and $C_{r 1}$ constitute a resonant circuit while $L_{r 2}$ and $C_{r 2}$ are idle. As the gating signals $v_{G S 1}$ and $v_{G S 4}$ turn from high to low at $t=t_{5}, Q_{1}$ and $Q_{4}$ cut off, and this stage ends.

\subsubsection{Stage $V\left[t_{5}<t \leq t_{6}\right]$}

As shown in Figure 6e, $Q_{1}$ and $Q_{4}$ are cut off at $t=t_{5}$ while $Q_{2}, Q_{3}$ still remain at the cut-off state. This exactly marks the dead time region with resonant current $i_{L r 1}$ charging the parasitic capacitors $C_{O S S 1}$ and $C_{O S S 4}$ as well as helping $C_{O S S 2}$ and $C_{O S S 3}$ to discharge. In the secondary side, $D_{B 6}$ and $D_{B 7}$ conduct, and $D_{B 5}$ and $D_{B 8}$ cut off. When the voltages on $C_{O S S 2}$ and $C_{O S S 3}$ are discharged to 0 and simultaneously $C_{O S S 1}$ and $C_{O S S 4}$ are charged to $V_{D C_{-} \text {Grid, }}$, this stage terminates.

The abovementioned process from Stage I to Stage $V$ constitutes the whole operation procedure during the positive cycle. The negative cycle has similar operating stages and thus is omitted here.

\section{Equivalent Circuit and Mathematic Formulation}

For obtaining the voltage gain and its relationship with respect to frequency, the fundamental harmonic approximation method (FHA) [19] was used to build the equivalent circuit model of the forward charging mode as illustrated in Figure 7 [20]. Here, $V_{D C_{-} \text {Grid_FHA }}$ is the fundamental component of the square voltage waveform at the primary side. $V_{o e}$ is the fundamental component of the square voltage waveform of the resonant tank and transformer. The resonant capacitance at the primary side, resonant inductance at the primary side, magnetizing inductance, resonant capacitance at the secondary side, and resonant capacitance at the secondary side are designated as $C_{r 1}, L_{r 1}, L_{m}$, $C_{r 2}{ }^{\prime}$, and $L_{r 2}{ }^{\prime}$, respectively. Moreover, power equivalent load resistance $R_{o e}$ is the AC load resistance of the energy storage battery referred to the primary side and is expressed as (1).

$$
R_{o e}=\frac{8 N^{2}}{\pi^{2}} \cdot \frac{V_{B a t}}{I_{B a t}}=\frac{8 N^{2}}{\pi^{2}} R_{B a t}
$$

where $N$ is the transformer turn ratio, and $R_{B a t}$ is the equivalent resistance of battery pack. For obtaining the transfer function of voltage gain, the Laplace transform of the ratio between the output voltage and the input voltage is derived as follows.

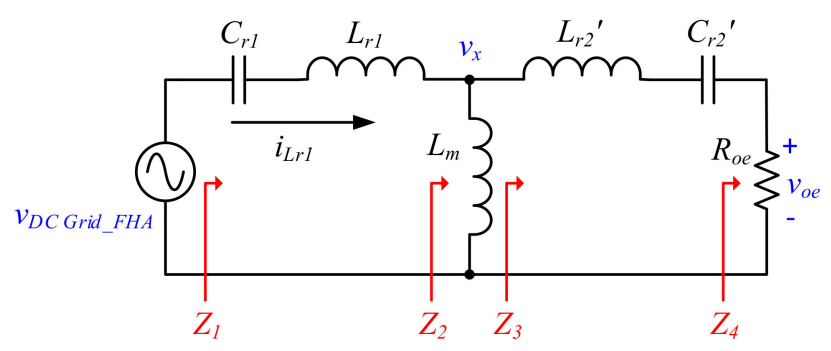

Figure 7. AC equivalent circuit of converter in the forward operation. 
First, the node voltage on the transformer is assigned as $v_{x}$, and based on basic circuit theory, (2) is obtained.

$$
v_{x}(s)=v_{D C} \operatorname{Grid}_{-} F H A(s) \cdot \frac{Z_{2}(s)}{Z_{1}(s)} v_{o e}(s)=v_{x}(s) \cdot \frac{Z_{4}(s)}{Z_{3}(s)}
$$

In (2), $Z_{1}(s), Z_{2}(s), Z_{3}(s)$, and $Z_{4}(s)$ are the Laplace forms of $Z_{1}, Z_{2}, Z_{3}$, and $Z_{4}$, respectively, looking from different positions, and are as expressed by (3).

$$
Z_{1}(s)=s L_{r 1}+\frac{1}{s C_{r 1}}+Z_{2}(s) Z_{2}(s)=\frac{s L_{m} \cdot\left(s L_{r 2}^{\prime}+\frac{1}{s C_{r 2^{\prime}}}+R_{o e}\right)}{s L_{m}+s L_{r 2^{\prime}}+\frac{1}{s C_{r 2^{\prime}}}+R_{o e}} Z_{3}(s)=s L_{r 2^{\prime}}+\frac{1}{s C_{r 2} \prime}+R_{o e} Z_{4}(s)=R_{o e}
$$

By properly rearranging (2) and (3), the voltage gain function of the forward charging mode can be given as (4).

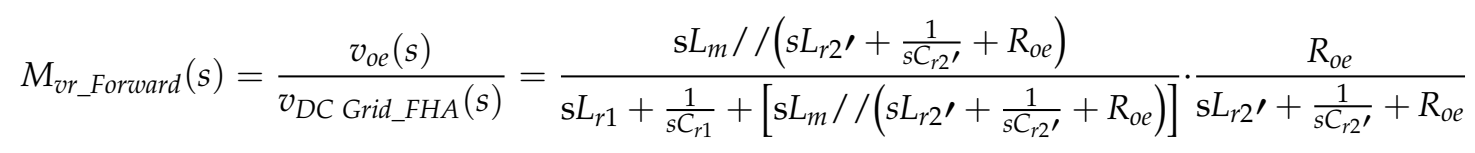

In addition, for simplifying the mathematic operation and for easily observing the gain curve, some definitions are described as follows: $f_{s}$ is the switching frequency of power switches; $f_{r 1 \_} F$ is the first resonant frequency; $f_{n_{-} F}$ is the ratio of $f_{s}$ and $f_{r 1_{-} F}$, referred to as normalized frequency; $Q_{1}$ represents quality factor; $k_{1}$ is the ratio of $L_{m}$ and $L_{r 1} ; g_{1}$ and $m_{1}$ represent the resonant capacitor ratio and resonant inductance ratio, respectively, with reference to the primary side. These are written as follows:

$$
\begin{gathered}
f_{r 1 \_F}=\frac{1}{2 \pi \sqrt{L_{r 1} C_{r 1}}}, f_{n}=\frac{f_{s}}{f_{r 1 \_} F}, Q_{1}=\frac{\sqrt{\frac{L_{r 1}}{C_{r 1}}}}{R_{o e}}, k_{1}=\frac{L_{m}}{L_{r 1}}, g_{1}=\frac{C_{r 2}{ }^{\prime}}{C_{r 1}}, m_{1}=\frac{L_{r 2} \prime}{L_{r 1}} \\
C_{r 1}=\frac{1}{2 \pi f_{r 1 \_} Q_{1} R_{o e}} \\
L_{r 1}=\frac{Q_{1} R_{o e}}{2 \pi f_{r 1 \_} F}
\end{gathered}
$$

By substituting the above defined quantities into (4), it yields (8), where $C_{r 1}$ and $L_{r 1}$ are expressed as (6) and (7).

$$
\begin{aligned}
& M_{\text {vr_Forward }}\left(f_{n_{-} F}\right)= \\
& 1 \\
& \sqrt{\left[1+\frac{1}{k_{1}}-\frac{1}{k_{1}\left(f_{n_{-} F}\right)^{2}}\right]^{2}+Q_{1}{ }^{2}\left[f_{n_{-} F}-\frac{1}{k_{1} g_{1} f_{n_{-} F}}-\frac{1}{f_{n_{-} F}}-\frac{1}{g_{1} f_{n_{-} F}}+\frac{1}{k_{1} g_{1}\left(f_{n_{-} F}\right)^{3}}+\frac{m_{1} f_{n_{-} F}}{k_{1}}-\frac{m_{1}}{k_{1} f_{n_{-} F}}+f_{n_{-} F} m_{1}\right]^{2}}
\end{aligned}
$$

Similarly, the voltage gain of the reverse discharging mode can be derived as well. The FHA AC equivalent circuit model of reverse mode is shown in Figure 8.

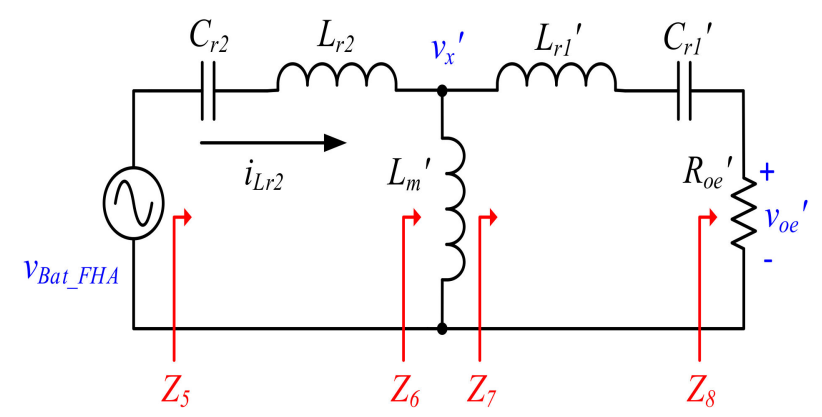

Figure 8. AC equivalent circuit of converter in the reverse operation. 
By applying the same conduction, the voltage gain transfer function of the reverse discharging mode can be expressed by (9).

$$
\begin{aligned}
& M_{\text {vr_Reverse }}\left(f_{n_{-} R}\right)= \\
& 1 \\
& \sqrt{\left[1+\frac{1}{k_{2}}-\frac{1}{k_{2}\left(f_{n_{-} R}\right)^{2}}\right]^{2}+Q_{2}{ }^{2}\left[f_{n_{-} R}-\frac{1}{k_{2} g_{2} f_{n_{-} R}}-\frac{1}{f_{n_{-} R}}-\frac{1}{g_{2} f_{n_{-} R}}+\frac{1}{k_{2} g_{2}\left(f_{n_{-} R}\right)^{3}}+\frac{m_{2} f_{n_{-} R}}{k_{2}}-\frac{m_{2}}{k_{2} f_{n_{-} R}}+f_{n_{-} R} m_{2}\right]^{2}}
\end{aligned}
$$

where the simplified parameters $f_{n_{-}}, Q_{2}, k_{2}, g_{2}$, and $m_{2}$ are defined below.

$$
f_{r 1 \_}=\frac{1}{2 \pi \sqrt{L_{r 2} C_{r 2}}}, f_{n_{-} R}=\frac{f_{s}}{f_{r 1 \_} R}, Q_{2}=\frac{\sqrt{\frac{L_{r 2}}{C_{r 2}}}}{R_{o e^{\prime}}}, k_{2}=\frac{L_{m^{\prime}}}{L_{r 2}}, g_{2}=\frac{C_{r 1} \prime}{C_{r 2}}, m_{2}=\frac{L_{r 1} \prime}{L_{r 2}}
$$

\section{The Design Procedure of Circuit Component Parameters}

For meeting the performance requirements of the developed converter, some design prerequisites are listed as follows:

1. It must have a wide voltage range.

2. There must be soft switching of power switches.

3. Cost and size should be reduced under high frequency operation.

A good circuit design of resonant circuits is founded on selecting appropriate resonance parameters. Figure 9 illustrates a complete design flowchart of the bidirectional symmetric resonant converter with the step-by-step design procedures being described in the following.

\subsection{Step 1: Determining the Specification of Converter}

Based on the circuit topology, an isolated type bidirectional symmetric resonant converter with $1 \mathrm{~kW}$ output power was implemented to test the validity of the conception. The specification of the converter is listed in Table 1.

Table 1. Converter specifications.

\begin{tabular}{cc}
\hline Parameters & Specifications \\
\hline DC grid voltage $V_{D C}$ Grid & $400 \mathrm{~V}$ \\
Battery port voltage $V_{\text {Bat }}$ & $280-403 \mathrm{~V}$ \\
Max. conversion power $P$ & $1000 \mathrm{~W}$ \\
Series resonant frequency $f_{r 1}$ & $100 \mathrm{kHz}$ \\
Power switching range $f_{s}$ & $70-150 \mathrm{kHz}$ \\
\hline
\end{tabular}

\subsection{Step 2: Calculating the Transformer Turn Ratio}

Following the determination of converter specifications, the proper transformer turn ratio was chosen immediately. For obtaining the flexibility of the tuning range, the transformer parameter design as expressed by (11) is based on the rated output voltage of the energy storage/supply port according to the battery nominal voltage.

$$
N=\frac{N_{P}}{N_{S}}=\frac{V_{D C \text { Grid_nom }}}{V_{\text {Bat_nom }}}
$$




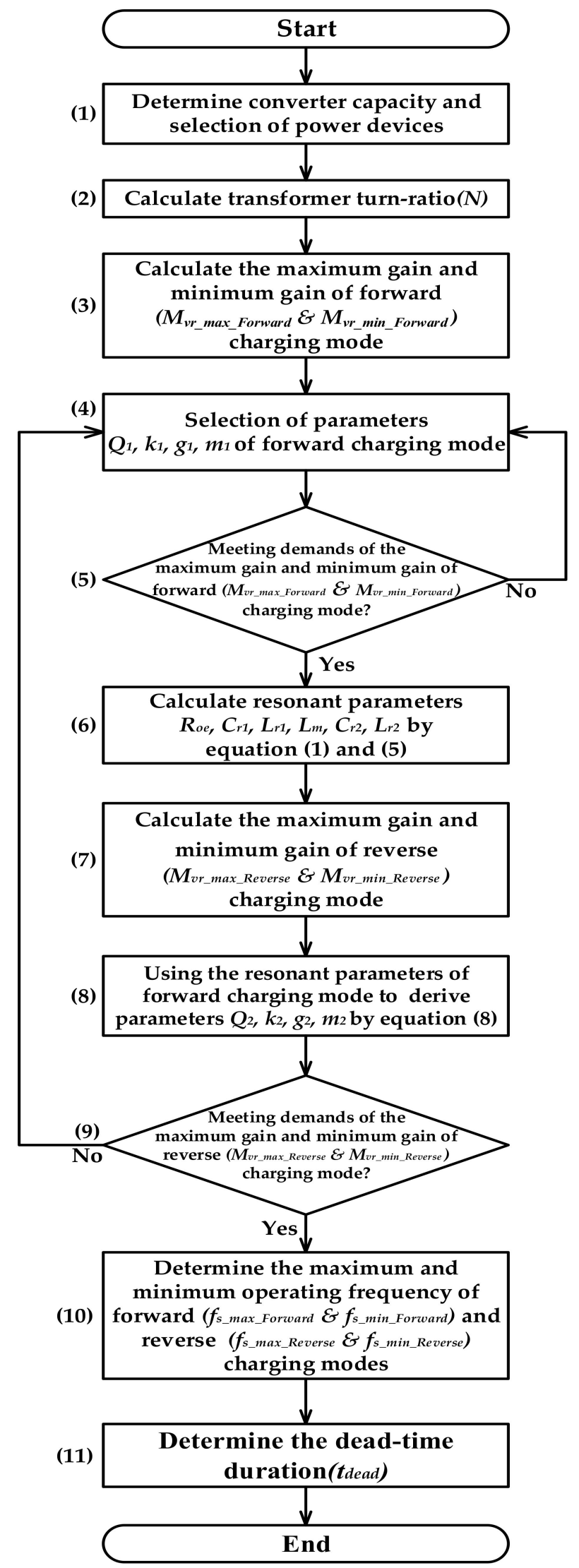

Figure 9. The design flowchart of bidirectional symmetric resonant converter. 


\subsection{Step 3: Calculating the Maximum and the Minimum Voltage Gains of Forward Mode}

Step 2 determines the transformer turn ratio to be approximately at 1.2. By applying (12) and (13), the maximum and the minimum gains of the forward charging mode are obtained.

$$
\begin{aligned}
& M_{v r \_ \text {max }}=\frac{N \cdot V_{\text {Bat_max }}}{V_{D C \text { Grid_nom }}}=\frac{1.2 \cdot 403}{400} \cong 1.21 \\
& M_{\text {vr_min }}=\frac{N \cdot V_{\text {Bat_min }}}{V_{\text {DC Grid_nom }}}=\frac{1.2 \cdot 280}{400}=0.84
\end{aligned}
$$

\subsection{Step 4: Selecting Parameters of $Q_{1}, k_{1}, g_{1}$, and $m_{1}$ to Meet the Forward Voltage Gain Requirement}

Initially, a set of proper parameter quantity was selected. Figure 10 shows the forward voltage gain with $k_{1}, g_{1}$, and $m_{1}$ being fixed and the forward mode quality factor $Q_{1}$ being adjusted. It clearly shows that the voltage gain curve is not a monotonic one and $Q_{1}$ with $0.6-2$ cannot realize the maximum and minimum gain requirement. Moreover, if $Q_{1}=0.4$, the operating range of switching frequency is too wide and will result in longer response time. Therefore, a value of $Q_{1}=0.2$ is suitable for the forward charging mode. With the same consideration, the selection of $k_{1}, g_{1}$, and $m_{1}$ is to meet the maximum and minimum gain as the primary priority.

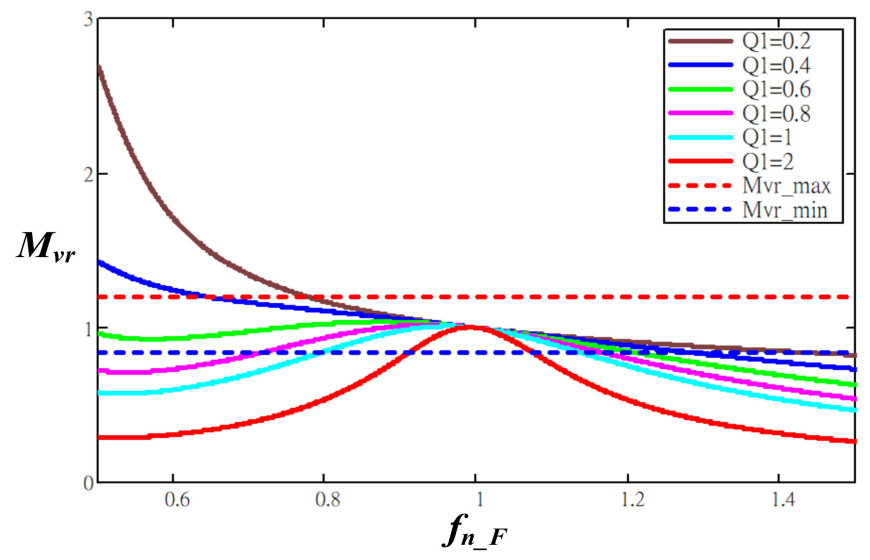

Figure 10. Voltage gain curves with different Q1 and fixed $k_{1}, g_{1}$, and $m_{1}$.

Due to the bidirectional operation of the proposed circuit, the resonant parameters must meet the voltage regulation of both the forward and reverse charging modes. The parameter design can only be fulfilled by an iterative process. Finally, the design parameters are $Q_{1}=0.2, k_{1}=3.5, g_{1}=1$, and $m_{1}=1$, as shown in Figure 11.

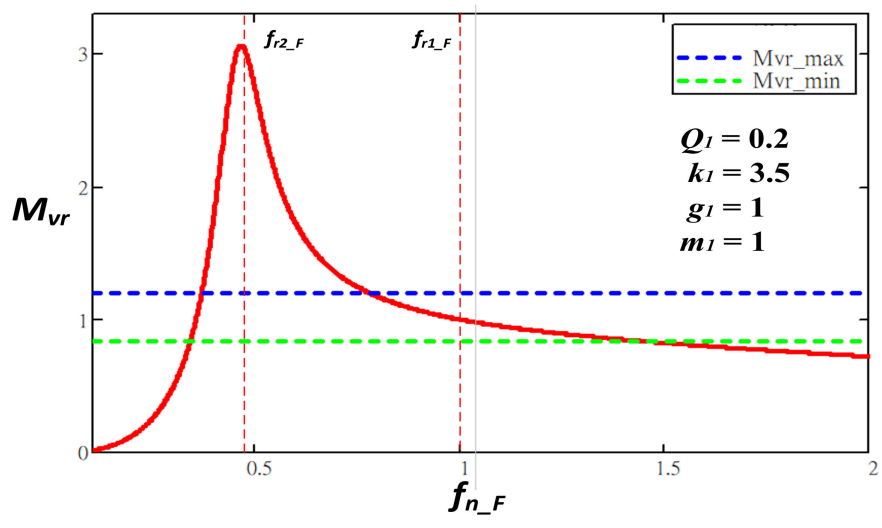

Figure 11. The voltage gain curves operating in the forward charging mode. 


\subsection{Step 5: Checking the Maximum and the Minimum Gains of the Forward Charging Mode}

If the maximum and the minimum gains of the forward charging mode are not met, the design has to return to Step 4 to update the parameters $Q_{1}, k_{1}, g_{1}$, and $m_{1}$. As the conditions are met, the design can go on to the next step.

\subsection{Step 6: Calculating the Resonant Device Parameters}

After the quantities $Q_{1}, k_{1}, g_{1}$, and $m_{1}$ are determined, the parameters of the associated resonant devices with device parameters $R_{o e}, C_{r 1}, L_{r 1}, L_{m}, C_{r 2}$, and $L_{r 2}$ can be obtained by (14) to (19).

$$
\begin{gathered}
R_{o e}=\frac{8 N^{2}}{\pi^{2}} \cdot \frac{V_{\text {Bat }}}{I_{\text {Bat }}}=\frac{8 \cdot 1.2^{2}}{\pi^{2}} \cdot \frac{403}{2.5} \cong 188.16 \Omega \\
C_{r 1}=\frac{1}{2 \cdot \pi \cdot f_{r 1 \_} \cdot Q_{1} \cdot R_{o e}}=\frac{1}{2 \cdot \pi \cdot 100 \mathrm{k} \cdot 0.2 \cdot 188.16} \cong 42.29 n \mathrm{~F} \\
L_{r 1}=\frac{1}{\left(2 \pi f_{r 1 \_F}\right)^{2} \cdot C_{r 1}}=\frac{1}{(2 \cdot \pi \cdot 100 \mathrm{k})^{2} \cdot 42.29 n} \cong 59.90 \mu \mathrm{H} \\
L_{m}=k_{1} \cdot L_{r 1}=3.5 \cdot 59.9 \mu=209.65 \mu \mathrm{H} \\
C_{r 2}=g_{1} \cdot N^{2} \cdot C_{r 1}=1 \cdot 1.2^{2} \cdot 42.29 n \cong 60.90 n F \\
L_{r 2}=\frac{L_{r 1} \cdot m_{1}}{N^{2}}=\frac{59.89 u \cdot 1}{1.2^{2}} \cong 41.60 u \mathrm{H}
\end{gathered}
$$

\subsection{Step 7: Calculating the Maximum and the Minimum Voltage Gains of Reverse Mode}

According to (20) and (21), the maximum and the minimum gains of the reverse charging mode can be achieved.

$$
\begin{aligned}
& M_{\text {max }}=\frac{V_{D C \text { Grid_nom }}}{N \cdot V_{\text {Bat_min }}}=\frac{400}{1.2 \cdot 280} \cong 1.19 \\
& M_{\text {min }}=\frac{V_{D C \text { Grid_nom }}}{N \cdot V_{\text {Bat_max }}}=\frac{400}{1.2 \cdot 403} \cong 0.83
\end{aligned}
$$

4.8. Step 8: Using the Resonant Device Parameters of Step 6 to Reversely Obtain the Parameters $Q_{2}, k_{2}, g_{2}$, and $m_{2}$ of the Reverse Discharging Mode

Employing the resonant device parameters obtained from the forward charging mode and backwards, we can calculate the parameters $Q_{2}, k_{2}, g_{2}$, and $\mathrm{m}_{2}$ of the reverse discharging mode.

\subsection{Step 9: Checking the Maximum and the Minimum Gains of the Reverse Charging Mode}

Mathcad is applied to examine whether the gains meet the maximum and minimum gain requirements illustrated in Figure 12. If the gain curves of reverse charging mode cannot satisfy the maximum and minimum gains condition, we will need to return to Step 4 to readjust the amount of $Q_{1}, k_{1}, g_{1}$, and $m_{1}$ recursively until the voltage gains of both forward and backward mode meet the requirements.

4.10. Step 10: Determining the Maximum and Minimum Operating Frequencies of the Forward and Reverse Charging Modes

By inspecting Figure 12, the maximum and minimum operating frequencies of the forward $\left(f_{s_{-} m a x}\right.$ Forward and $\left.f_{s_{-} \text {min_Forward }}\right)$ and reverse $\left(f_{s_{-} m a x \_R e v e r s e}\right.$ and $\left.f_{s_{-} \text {min_Reverse }}\right)$ charging modes can be calculated. 


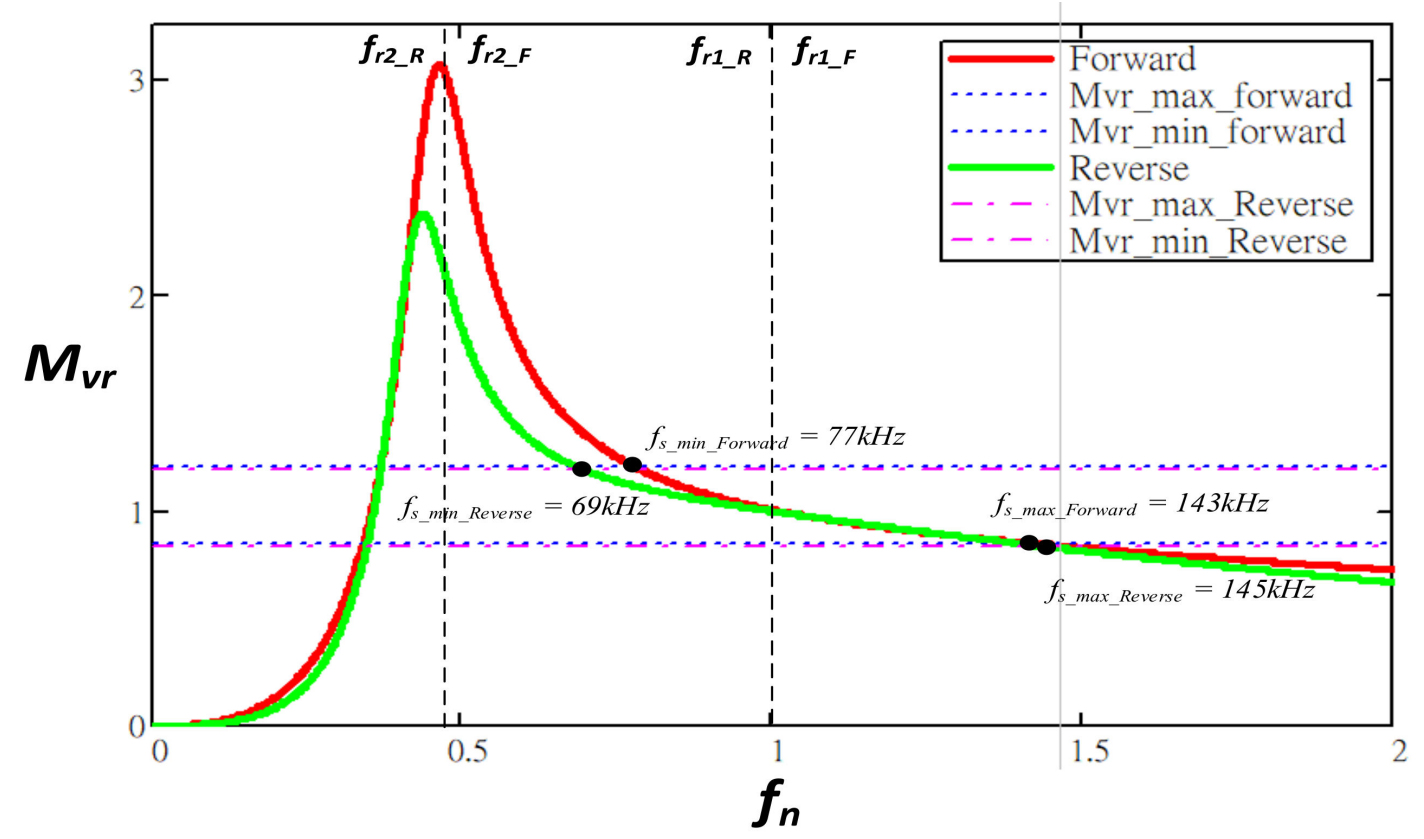

Figure 12. The voltage gain curves operating in the forward and reverse charging modes.

\subsection{Step 11: Determining the Duration of Dead Time $\left(t_{\text {dead }}\right)$}

The duration of dead time plays the key role of success or failure of ZVS of power switches. Too short of a dead time will lead to the unsuccessful removal of the charge on the parasitic capacitors of the power switches and yield ZVS failure while too long of a dead time would sacrifice the energy propagation time and thus increase the current stress on the primary side [21]. Therefore, the silicon carbide (SiC) NMOS power switches C2M0160120D manufactured by the CREE Inc. with very small parasitic capacitance $C_{O S S}$ being equal to $55 \mathrm{pF}$ are used, and thus the ZVS is easily accomplished. By using (22), the required dead time can be attained.

$$
t_{\text {dead }} \geq 8 \cdot C_{\text {OSS }} \cdot f_{s_{-} \text {max }} \cdot L_{m}=8 \cdot 55 p \cdot 145 k \cdot 209.65 u \cong 13.38 n s
$$

Because the stray capacitance and parasitic inductance are not taken into account, the dead-time interval was kept up to $200 \mathrm{~ns}$ for more tolerance.

\section{The Structure of the Digital Signal Control System}

Figure 13 shows the control system structure of the developed isolated bidirectional symmetric resonant converter. The digital signal processor (DSP) IC TMS320F28335 of Texas Instruments was employed as the control core of this bidirectional converter system to manipulate the bidirection power flow approach. In comparison with the analog scheme, the digital signal approach can effectively reduce the amount of circuit component and thus decrease the size and cost accordingly.

\subsection{Control Strategy}

In this research, the constant current-constant voltage control is determined as the charging strategy of battery storage. In the battery discharging mode, the constant voltage control is applied to keep the stability and reliability of the DC power grid. 
Taking the battery storage as an example, Figure 14 shows the control system block diagram of the battery storage [22,23], with the reference voltage signal $V_{b_{-} \text {ref }}$ being $95 \%$ of the upper limit battery voltage and $I_{b_{-} r e f}$ being the reference current signal according to the battery charging current. When the battery is charged in the constant-current mode, the analog-to-digital converter (ADC) of the DSP will fetch the output signal $I_{b}$ and compare it with the reference current signal $I_{b_{-}}$ref to obtain the difference. With the compensation by a Proportional integrator (PI) controller and modulation by a frequency modulation generator (FM generator), a frequency modulated pulse-width modulation (PWM) is achieved to accomplish the constant current control.

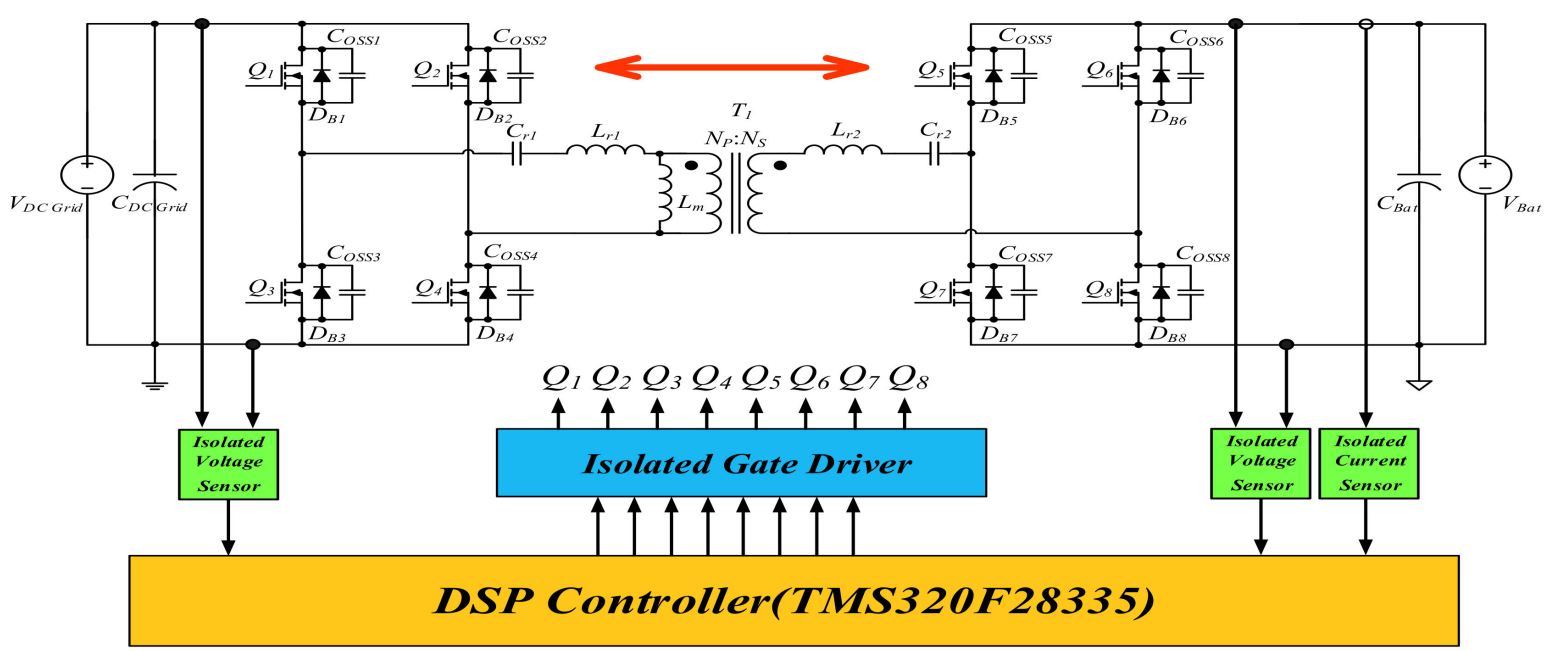

Figure 13. The overall system structure of the isolated bidirectional symmetric resonant converter.

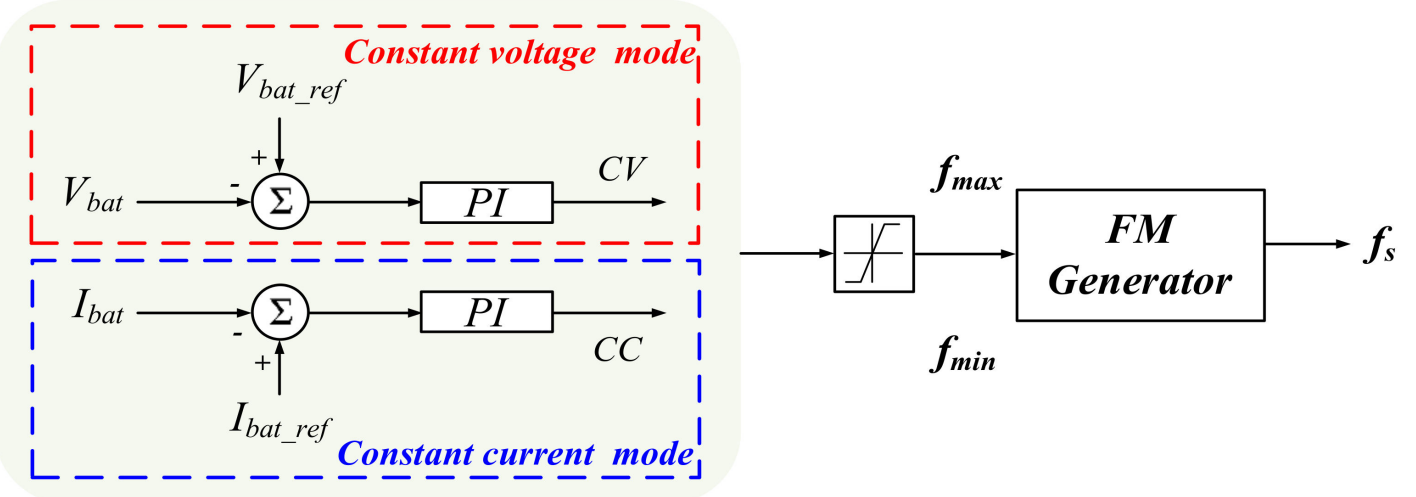

Figure 14. The functional block diagram of the battery storage.

\subsection{The Step Response Test of the Charging Current}

Although the constant current-constant voltage control is the charging strategy, most of the charging time is based on the constant current charging. Thus, an abrupt constant current charging fluctuation is proposed to validate the developed scheme.

Figure 15 shows the voltage and current curves under a step load current change. In Figure 15a, the battery voltage is kept constant when load current is drastically increased, while Figure $15 \mathrm{~b}$ reveals that the battery voltage remains unchanged under an abrupt load current drop. It can be clearly observed that the battery voltage remains constant when load current fluctuates. 


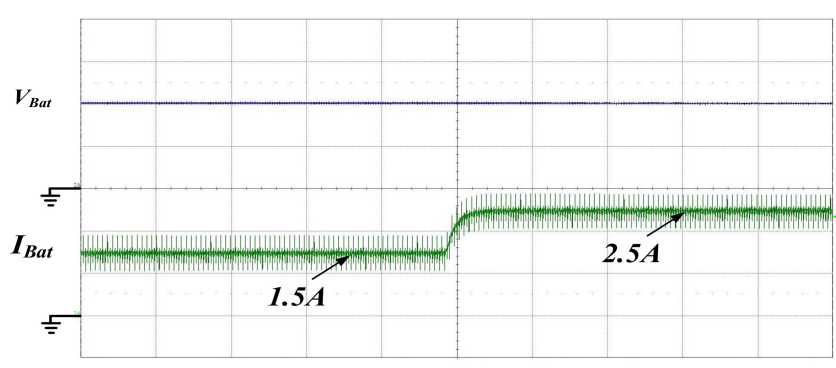

$V_{\text {Bat: }} 200$ V/div, IBat: 1 A/div, Time: $200 \mu$ s/div $V_{\text {Bat }}=403 \mathrm{~V}, I_{\text {Bat }}=1.5 \mathrm{~A}$ to $I_{\text {Bat }}=2.5 \mathrm{~A}$

(a)

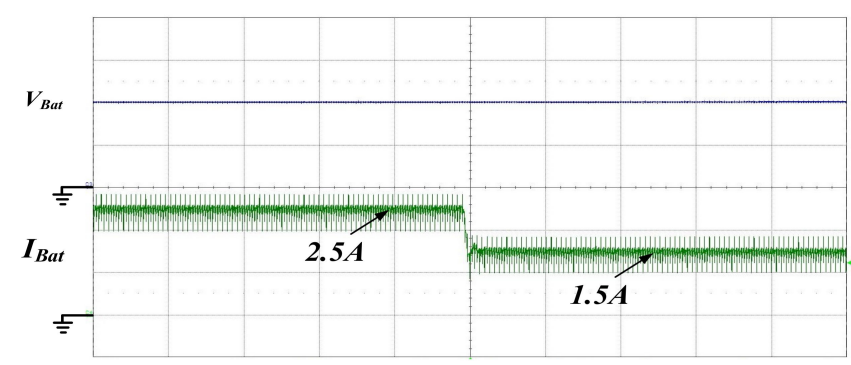

$V_{\text {Bat: }} 200$ V/div, IBat: 1 A/div, Time: $200 \mu$ s/div $V_{\text {Bat }}=403 \mathrm{~V}, I_{\text {Bat }}=2.5 \mathrm{~A}$ to $I_{\text {Bat }}=1.5 \mathrm{~A}$

(b)

Figure 15. The voltage state under abrupt load current fluctuation: (a) load current changes from $1.5 \mathrm{~A}$ to $2.5 \mathrm{~A}$; (b) load current changes from $2.5 \mathrm{~A}$ to $1.5 \mathrm{~A}$.

\section{The Measurements and Operating Efficiency Analysis}

Based on the parameters, the resonant components are calculated with $L_{r 1}=59.9 \mu \mathrm{H}, L r 2=41.6 \mu \mathrm{H}$, $L_{m}=209.65 \mu \mathrm{H}, C_{r 1}=42.29 \mathrm{nF}$, and $C_{r 2}=60.9 \mathrm{nF}$. Owing to the winding transformer's windings and resonant inductor being handmade, there definitely exists some differences from the calculated ones. Indeed, the transformer magnetizing inductance $L_{m}$ was measured to be $219.85 \mu \mathrm{H}$, and the primary and secondly leakage inductances are $L_{l k 1}=6 \mu \mathrm{H}$ and $L_{l k 2}=4 \mu \mathrm{H}$, respectively. Moreover, two resonant inductances are $L_{r 1}=55.2 \mu \mathrm{H}$ and $L_{r 2}=40.36 \mu \mathrm{H}$. The resonant capacitors are connected in parallel; it not only can divert the current flow, but it also can reduce the current stress of each capacitor and decrease equivalent series resistance (ESR) loss with $C_{r 1}=41.4 \mathrm{nF}$ and $C_{r 2}=53.7 \mathrm{nF}$.

Table 2 lists the selected parameters of the important devices in the practical circuit. The microcontroller unit (MCU) TMS320F28335 developed by TI was selected as the control core of bidirectional power flow to effectively dwindle the amount of device and reduce the size and cost. Considering the cost and the fast switching feature, the wide-band gap SiC (C2M0160120D) is used to serve the power switches $\left(Q_{1}-Q_{8}\right)$ to promote the converter's performance.

Table 2. Selected parameters of the important devices.

\begin{tabular}{cc}
\hline Device Symbol & Quantity \\
\hline Transformer turn ratio $N_{P}: N_{S}$ & $1.2: 1$ \\
Magnetizing inductance $L_{m}$ & $219.85 \mu \mathrm{H}$ \\
Resonant inductance $L_{r 1}$ (including primary leakage inductance) & $61.2 \mu \mathrm{H}$ \\
Resonant inductance $L_{r 2}$ (including secondary leakage inductance) & $44.36 \mu \mathrm{H}$ \\
Resonant capacitance (primary) $C_{r 1}$ & $41.4 \mathrm{nF}$ \\
Resonant capacitance (secondary) $C_{r 2}$ & $53.7 \mathrm{nF}$ \\
DC grid capacitor tank $C_{D C}$ Grid & $540 \mu \mathrm{F}$ \\
Battery capacitor tank $C_{\text {Bat }}$ & $540 \mu \mathrm{F}$ \\
Power switches $Q_{1}-Q_{8}$ & C2M0160120D \\
Trigger controller & TMS320F28335 \\
\hline
\end{tabular}




\subsection{Critical Measurements for the Forward Charging Mode}

Figure 16 shows the measurement results of $v_{G S 3}, v_{D S 3}$, and $i_{D S 3}$ in the cases where $V_{D C}$ Grid $=400 \mathrm{~V}$ and charging battery voltages are $V_{B a t}=280 \mathrm{~V}$ and $V_{B a t}=403 \mathrm{~V}$ respectively. It is obvious that there appears a reverse current $i_{D S 3}$ inside the power switch both in Figure 16a,b which helps remove the energy on the parasitic capacitance and rapidly decline $V_{D S 3}$ to $0 \mathrm{~V}$, thus achieving ZVS.

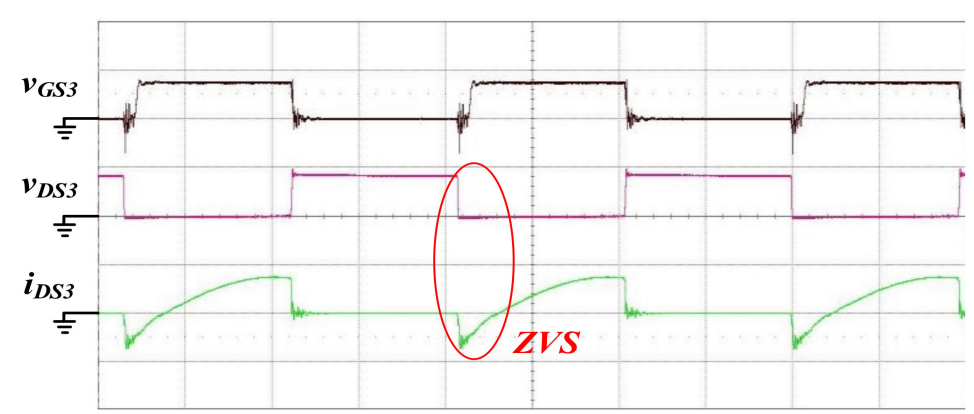

vGS3: $20 \mathrm{~V} / \mathrm{div}, v_{D S 3}: 500 \mathrm{~V} / \mathrm{div}, i_{D S 3}: 10 \mathrm{~A} / \mathrm{div}$, Time: $2 \mu \mathrm{s} / \mathrm{div}$

$V_{D C_{-} \text {Grid }}=400 \mathrm{~V}, V_{\text {Bat }}=280 \mathrm{~V}$

(a)

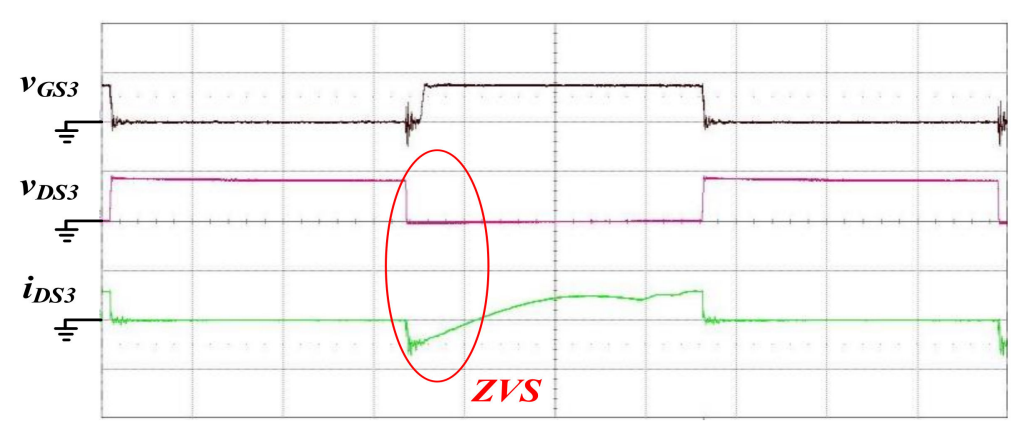

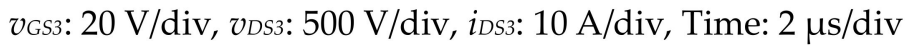

$$
V_{D C_{-} \text {Grid }}=400 \mathrm{~V}, V_{\text {Bat }}=403 \mathrm{~V}
$$

(b)

Figure 16. Waveforms of $v_{G S 3}, v_{D S 3}$, and $i_{D S 3}$ with two battery voltages: (a) $V_{B a t}=280 \mathrm{~V}$; (b) $V_{B a t}=403 \mathrm{~V}$.

Figure 17 shows the measurement results of $v_{D B 7}$ and $i_{D B 7}$ in the cases where $V_{D C_{-} \text {Grid }}=400 \mathrm{~V}$ and charging battery voltages are $V_{B a t}=280 \mathrm{~V}$ and $V_{B a t}=403 \mathrm{~V}$, respectively. By observing Figure 17a, the diode current $i_{D B 7}$ has not fallen to 0 A prior to the cut-off of diode $\mathrm{D}_{\mathrm{B} 7}$ and thus leads to diode ZCS failure. Figure $17 \mathrm{~b}$ shows that the diode current $i_{D B 7}$ has reached $0 \mathrm{~A}$ before diode $D_{B 7}$ turns off and thus succeeds in the ZCS of $D_{B 7}$. It is worth noting that the oscillation of $v_{D B 7}$ at the switching instant resulted from the resonance of parasitic capacitance and resonant inductance.

\subsection{Critical Measurements for the Reverse Discharging Mode}

Figure 18 shows the measurement results of $v_{G S 8}, v_{D S 8}$, and $i_{D S 8}$ in the cases where the discharging battery voltages are $V_{B a t}=280 \mathrm{~V}$ and $V_{B a t}=403 \mathrm{~V}$, respectively, and $V_{D C_{-} \text {Grid }}=400 \mathrm{~V}$. It is obvious that there appears a reverse current $i_{D S 8}$ inside the power switch both in Figure 18a,b, which helps remove the energy on the parasitic capacitance and rapidly decline $\mathrm{v}_{\mathrm{DS} 8}$ to $0 \mathrm{~V}$, thus achieving ZVS.

Notably, Figure 19a clearly exhibits the advantage of a symmetric dual resonant converter in that the voltage gain is obviously greater than 1 . 


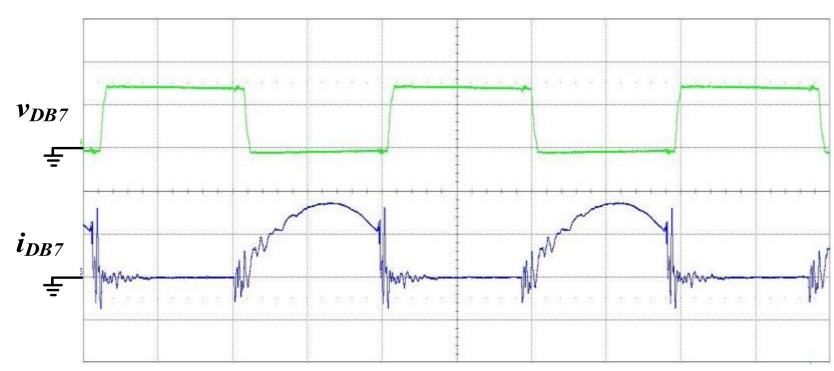

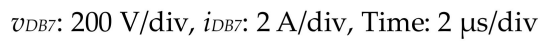
$V_{D C_{C} \text { Grid }}=400 \mathrm{~V}, V_{\text {Bat }}=280 \mathrm{~V}$

(a)

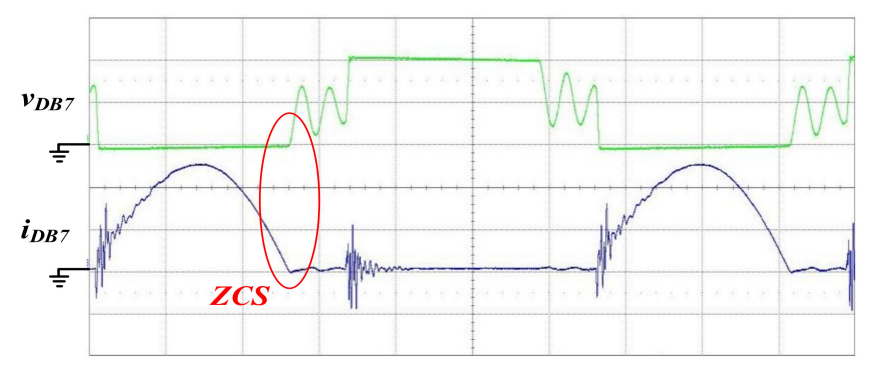

vDBz: $200 \mathrm{~V} / \mathrm{div}, i_{D B}: 2 \mathrm{~A} / \mathrm{div}$, Time: $2 \mu \mathrm{s} / \mathrm{div}$ $V_{D C_{-} \text {Grid }}=400 \mathrm{~V}, V_{\text {Bat }}=403 \mathrm{~V}$

(b)

Figure 17. Waveforms of $v_{D B 7}$ and $i_{D B 7}$ with two battery voltages: (a) $V_{B a t}=280 \mathrm{~V}$; (b) $V_{B a t}=403 \mathrm{~V}$.

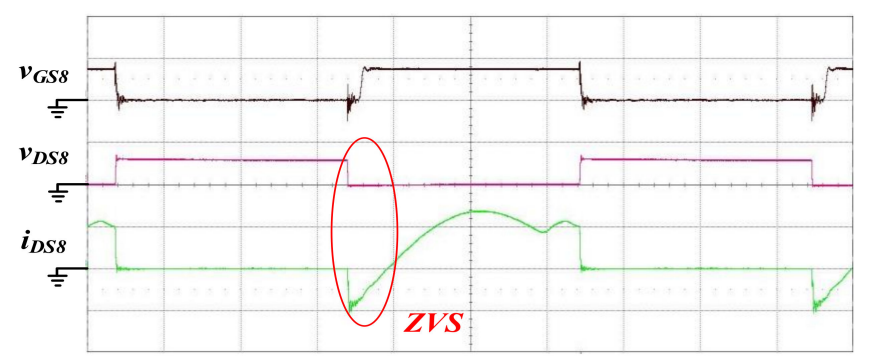

$v_{G S s}: 20 \mathrm{~V} / \mathrm{div}, v_{D S s}: 500 \mathrm{~V} / \mathrm{div}, i_{D S 8} 5 \mathrm{~A} / \mathrm{div}$, Time: $2 \mu \mathrm{s} / \mathrm{div}$ $V_{\text {Bat }}=280 \mathrm{~V}, V_{D C_{-} \text {Grid }}=400 \mathrm{~V}$

(a)

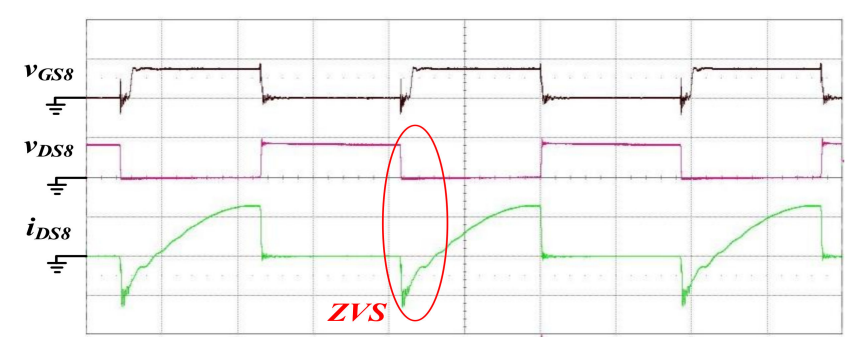

$v_{G S s}: 20 \mathrm{~V} / \mathrm{div}, v_{D S s}: 500 \mathrm{~V} / \mathrm{div}, i_{D S s}: 5 \mathrm{~A} / \mathrm{div}$, Time: $2 \mu \mathrm{s} / \mathrm{div}$ $V_{\text {Bat }}=403 \mathrm{~V}, V_{D C_{-} \text {Grid }}=400 \mathrm{~V}$

(b)

Figure 18. Waveforms of $v_{G S 8}, v_{D S 8}$, and $i_{D S 8}$ with two discharging battery voltages: (a) $V_{B a t}=280 \mathrm{~V}$; (b) $V_{\text {Bat }}=403 \mathrm{~V}$. 


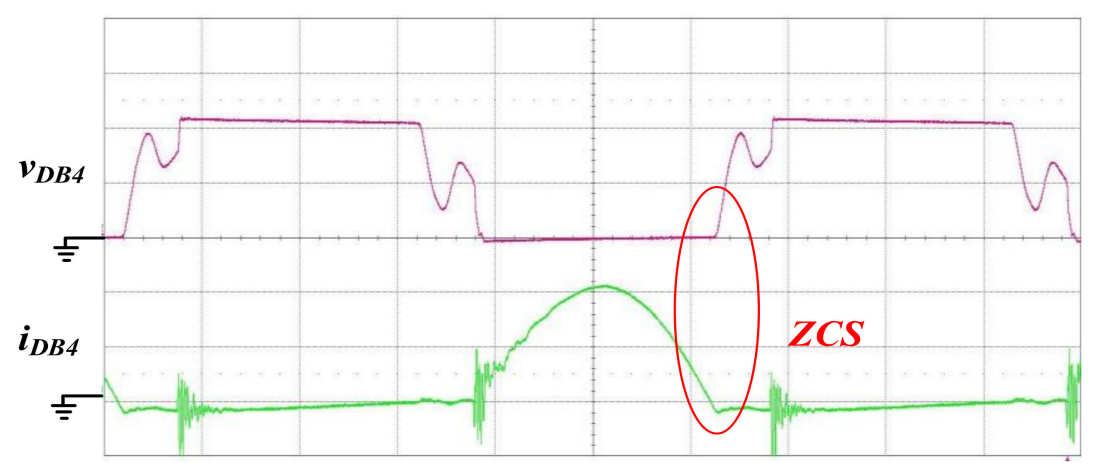

vDB4: $200 \mathrm{~V} / \mathrm{div}, i_{D B 4}: 2 \mathrm{~A} / \mathrm{div}$, Time: $2 \mu \mathrm{s} / \mathrm{div}$

$V_{\text {Bat }}=280 \mathrm{~V}, V_{D C_{-} G \text { rid }}=400 \mathrm{~V}$

(a)

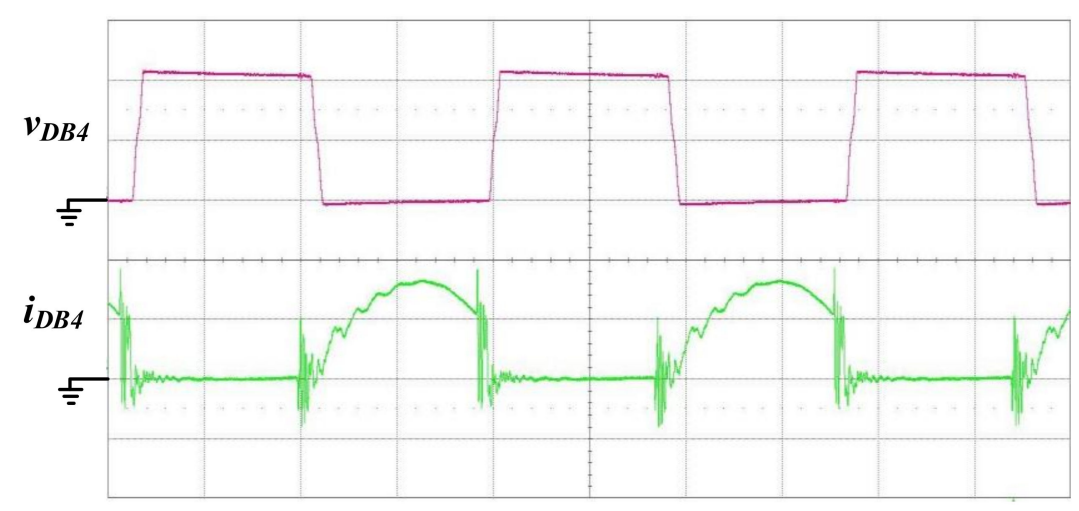

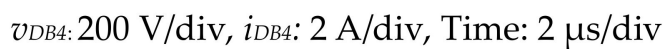

$V_{\text {Bat }}=403 \mathrm{~V}, V_{D C_{-} \text {Grid }}=400 \mathrm{~V}$

(b)

Figure 19. Waveforms of $v_{D B 4}$ and $i_{D B 4}$ with two discharging battery voltages: (a) $V_{B a t}=280 \mathrm{~V}$; (b) $V_{\text {Bat }}=403 \mathrm{~V}$.

Figure 19 shows the measurement results of $v_{D B 4}$ and $i_{D B 4}$ in the cases where the discharging battery voltages are $V_{B a t}=280 \mathrm{~V}$ and $403 \mathrm{~V}$, respectively, and the DC grid voltage $V_{D C \_G r i d}=400 \mathrm{~V}$. By observing Figure 19a, the diode current $i_{D B 4}$ has fallen to 0 A prior to the cut-off of diode $D_{B 4}$ and thus leads to diode ZCS being successful. It is worth noting that there appears oscillation of $v_{D B 4}$ at the switching instant, which resulted from the resonance of parasitic capacitance and the secondary resonant inductance. Due to the resonant converter working at Region I, Figure $19 \mathrm{~b}$ shows that the diode current $i_{D B 4}$ has not reached 0 A before diode $D_{B 4}$ turns off and thus fails in ZCS of $D_{B 4}$.

\subsection{Efficiency Plots for Forward Mode and Reverse Mode}

Figure 20 shows the efficiency curves with battery voltages $V_{\text {Bat }}$ being 280, 340, and $403 \mathrm{~V}$ and charging currents ranging from 0.5 to $2.5 \mathrm{~A}$. This reveals that the maximum conversion efficiency is $91.96 \%$ at the lowest battery voltage $280 \mathrm{~V}$, and the maximum conversion efficiency is $93.25 \%$ at the highest battery voltage $403 \mathrm{~V}$. The maximal efficiency of $93.67 \%$ appears in the case of the $340 \mathrm{~V}$ battery voltage because it gets near to the resonant point, and the total impedance is nearly 0 . In the forward charging mode, the voltage of DC grid is $400 \mathrm{~V}$, and the designed resonant frequency is around $100 \mathrm{kHz}$ at the $340 \mathrm{~V}$ battery voltage, thus getting higher efficiency due to the switching instants of the turn-on and cut-off being near the zero-crossing point. When the discharging current is low, although possessing both ZVS and ZCS, the effect is not obvious due to low current. As the current rises to $1.5 \mathrm{~A}$, the efficiency at battery voltage $403 \mathrm{~V}$ apparently surpasses that with $280 \mathrm{~V}$ battery voltage. 


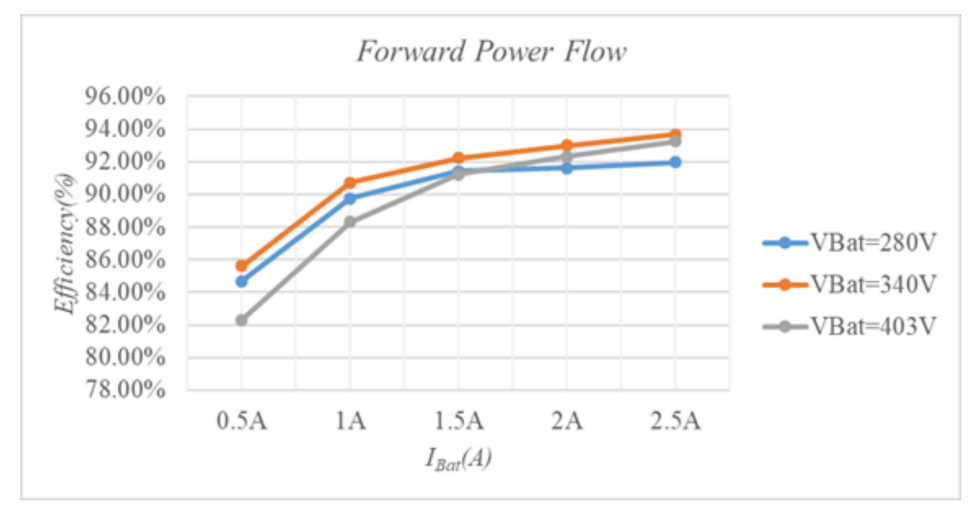

Figure 20. Conversion efficiency curves for the forward charging mode.

Figure 21 shows the efficiency curves with discharging voltages $V_{B a t}$ being 280, 340, and $403 \mathrm{~V}$ and discharging currents ranging from 0.5 to $2.5 \mathrm{~A}$. In the reverse discharging mode, the voltage of DC grid is $400 \mathrm{~V}$ as well. For low battery voltage level, it needs more voltage gain to fulfill DC grid charging and operates in the Region II due to low operating frequency. At different voltage levels of the battery, low battery voltage conditions need more current to discharge the constant voltage DC grid to achieve the identical power level and thus experience more relative power loss. In the case of a $280 \mathrm{~V}$ battery voltage, despite the converter operating in Region II and possessing ZCS on the rectifier side, its power loss rate is relatively higher. Operating at a $340 \mathrm{~V}$ battery voltage, even though the converter works near the resonant frequency and possesses the advantage of ZVS and ZCS, the conversion efficiency is better than that of the $403 \mathrm{~V}$ battery voltage due to more discharging current being needed for the identical power conversion. In fact, when the battery voltage is $403 \mathrm{~V}$ and operates at high frequency in Region I with only a ZVS mechanism, it achieves similar efficiency with that of $340 \mathrm{~V}$. This reveals that the maximum conversion efficiency is $91.3 \%$ at the lowest discharging voltage $280 \mathrm{~V}$, and the maximum conversion efficiency is $94.6 \%$ at the highest discharging voltage $403 \mathrm{~V}$.

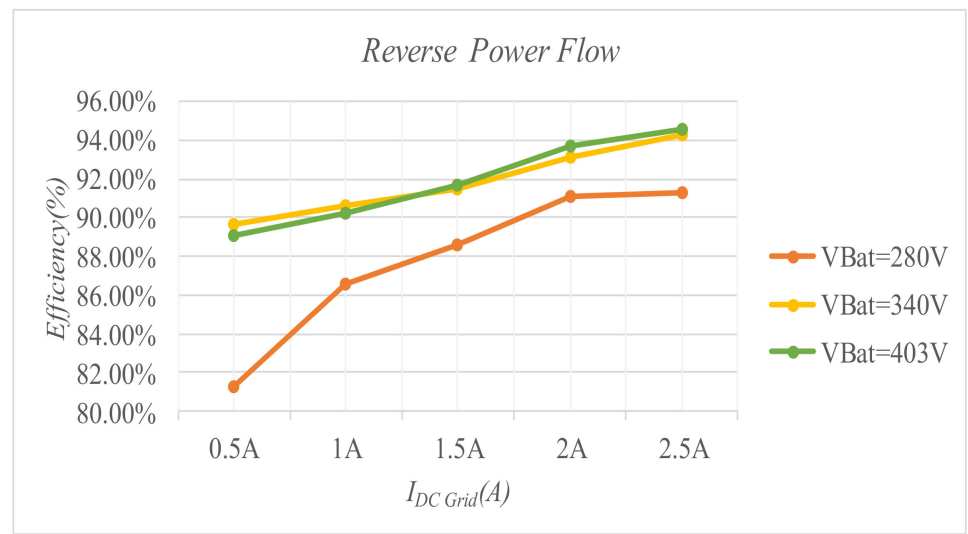

Figure 21. Conversion efficiency curves for the reverse discharging mode.

\section{Conclusions}

This research accomplished and realized an isolated type bidirectional symmetric resonant converter with a wide voltage range. By modifying the traditional LLC resonant topology, the secondary side rectifying diodes were replaced by active power switches to constitute a dual active bridge topology. With the introduction of a second set of resonant devices to the secondary side, the symmetric structure enabled the voltage gain to be greater than 1 . Indeed, the developed converter is featured with a wide voltage range due to symmetric topology and good conversion efficiency due to ZVS and ZCS functionality. Finally, a $1 \mathrm{~kW}$ bidirectional power flow converter that assigns one port with voltage $400 \mathrm{~V}$ and another port with voltage ranging from 280 to $403 \mathrm{~V}$ was accomplished. The measurements 
indicate that the maximum conversion efficiency can reach $93.25 \%$ in the forward charging mode and is as high as $94.60 \%$ in the reverse discharging mode.

Author Contributions: Y.-H.Y. conceived and designed the proposed resonant converter; Y.-N.C. performed the circuit simulation and designed the parameters of the converter components; Y.-D.C. carried out the prototype resonant converter and measured as well as analyzed the experimental results; S.-Y.C. wrote the paper, and H.-L.C. revised it for submission. All authors have read and agreed to the published version of the manuscript.

Funding: This research received no external funding.

Acknowledgments: This work was supported by the Ministry of Science and Technology, R.O.C. under the grant MOST 109-2221-E-150-021-MY2.

Conflicts of Interest: The authors declare no conflict of interest.

\section{References}

1. Ma, Z.; Pesaran, A.; Gevorgian, V.; Gwinner, D.; Kramer, W. Energy storage, renewable power generation, and the grid: NREL capabilities help to develop and test energy-storage technologies. IEEE Electrif. Mag. 2015, 3, 30-40. [CrossRef]

2. Babokany, A.S.; Jabbari, M.; Shahgholian, G.; Mahdavian, M. A review of bidirectional dual active bridge converter. In Proceedings of the 9th International Conference on Electrical Engineering/Electronics, Computer, Telecommunications and Information Technology; Institute of Electrical and Electronics Engineers (IEEE), Phetchaburi, Thailand, 16-18 May 2012; pp. 1-4.

3. Tytelmaier, K.; Husev, O.; Veligorskyi, O.; Yershov, R. A review of non-isolated bidirectional dc-dc converters for energy storage systems. In Proceedings of the 2nd International Young Scientists Forum on Applied Physics and Engineering (YSF), Kharkiv, Ukraine, 10-14 October 2016; pp. 22-28.

4. Zhao, B.; Yu, Q.; Sun, W. Bidirectional full-bridge DC-DC converters with dual phase-shifting control and its backflow power characteristic analysis. In Proceedings of the Chinese Society of Electrical Engineering, Bejing, China, 25 April 2012; pp. 43-50.

5. Zhao, B.; Song, Q.; Liu, W. Efficiency Characterization and Optimization of Isolated Bidirectional DC-DC Converter Based on Dual-Phase-Shift Control for DC Distribution Application. IEEE Trans. Power Electron. 2013, 28, 1711-1727. [CrossRef]

6. Zhao, B.; Song, Q.; Liu, W.; Sun, Y. Overview of dual-active-bridge isolated bidirectional DC-DC converter for high-frequency-link power-conversion system. IEEE Trans. Power Electron. 2013, 29, 4091-4106. [CrossRef]

7. Li, W.; Zhao, H.; Kan, T.; Mi, C. Inter-operability considerations of the double-sided LCC compensated wireless charger for electric vehicle and plug-in hybrid electric vehicle applications. In Proceedings of the IEEE PELS Workshop on Emerging Technologies: Wireless Power (2015 WoW), Daejeon, Korea, 5-6 June 2015; pp. 1-6.

8. Shafiei, N.; Saket, M.A.; Ordonez, M. Time domain analysis of LLC resonant converters in the boost mode for battery charger applications. In Proceedings of the IEEE Energy Conversion Congress and Exposition (ECCE), Cincinnati, OH, USA, 1-5 October 2017; pp. 4157-4162.

9. Liu, C.; Wang, J.; Colombage, K.; Gould, C.; Sen, B. A CLLC resonant converter based bidirectional EV charger with maximum efficiency tracking. In Proceedings of the 8th IET International Conference on Power Electronics, Machines and Drives (PEMD 2016), Glasgow, UK, 19-21 April 2016; pp. 1-6.

10. Dalala, Z.; Zahid, Z.U.; Saadeh, O.; Lai, J.S.J. Modeling and controller design of a bidirectional resonant converter battery charger. IEEE Access 2018, 6, 23338-23350. [CrossRef]

11. Pledl, G.; Tauer, M.; Buecherl, D. Theory of operation, design procedure and simulation of a bidirectional LLC resonant converter for vehicular applications. In Proceedings of the IEEE Vehicle Power and Propulsion Conference, Lille, France, 1-3 September 2010; pp. 1-5.

12. Chen, W.; Rong, P.; Lu, Z. Snubberless bidirectional DC-DC converter with new CLLC resonant tank featuring minimized switching loss. IEEE Trans. Ind. Electron. 2010, 57, 3075-3086. [CrossRef]

13. Lv, Z.; Yan, X.; Fang, Y.; Sun, L. Mode analysis and optimum design of bidirectional CLLC resonant converter for high-frequency isolation of DC distribution systems. In Proceedings of the IEEE Energy Conversion Congress and Exposition (ECCE), Montreal, QC, Canada, 20-24 September 2015; pp. 1513-1520. 
14. Tan, K.; Yu, R.; Guo, S.; Huang, A.Q. Optimal design methodology of bidirectional LLC resonant DC/DC converter for solid state transformer application. In Proceedings of the 40th IEEE Annual Conference of the IEEE Industrial Electronics Society, Dallas, TX, USA, 29 October-1 November 2014; pp. 1657-1664.

15. Jiang, T.; Zhang, J.; Wu, X.; Sheng, K.; Wang, Y. A Bidirectional LLC resonant converter with automatic forward and backward mode transition. IEEE Trans. Power Electron. 2015, 30, 757-770. [CrossRef]

16. Zhang, J.; Liu, J.; Yang, J.; Zhao, N.; Wang, Y.; Zheng, T.Q. An LLC-LC type bidirectional control strategy for an LLC resonant converter in power electronic traction transformer. IEEE Trans. Ind. Electron. 2018, 65, 8595-8604. [CrossRef]

17. Zong, S.; Fan, G.; Yang, X. Double Voltage Rectification Modulation for Bidirectional DC/DC Resonant Converters for Wide Voltage Range Operation. IEEE Trans. Power Electron. 2018, 34, 6510-6521. [CrossRef]

18. Song, J.; Yang, D.; Zhang, C.; Duan, B. Hybrid control method for CLLLC resonant converter with Low output voltage ripple. IFAC PapersOnLine 2018, 51, 680-684. [CrossRef]

19. Texas Instruments Power Supply Design Seminar. Designing an LLC Resonant Half-Bridge Power Converter; Texas Instruments Power Supply Design Seminar: Dallas, TX, USA, 2019.

20. Ditze, S. Steady-state analysis of the bidirectional CLLLC resonant converter in time domain. In Proceedings of the IEEE 36th International Telecommunications Energy Conference (INTELEC), Vancouver, BC, Canada, 28 September-2 October 2014; pp. 1-9.

21. Lu, B.; Liu, W.; Liang, Y.; Lee, F.; van Wyk, J. Optimal design methodology for LLC resonant converter. In Proceedings of the 21st Annual IEEE Applied Power Electronics Conference and Exposition, APEC'06, Dallas, TX, USA, 19-23 March 2006; pp. 533-538.

22. Luo, S.J. Implementation of a Dual-Active-Bridge Bidirectional Isolated DC to DC Converter in Home Area Network. Master's Thesis, Department of Electrical Engineering, National Sun Yat-Sen University, Kaohsiung City, Taiwan, 2012.

23. Liang, J.C. Contactless Li-Mn Battery Charger with Intelligent Control. Master's Thesis, Department of Electrical Engineering, National Central University, Taoyuan City, Taiwan, 2014.

Publisher's Note: MDPI stays neutral with regard to jurisdictional claims in published maps and institutional affiliations.

(C) 2020 by the authors. Licensee MDPI, Basel, Switzerland. This article is an open access article distributed under the terms and conditions of the Creative Commons Attribution (CC BY) license (http://creativecommons.org/licenses/by/4.0/). 